\title{
Intergenerational Transmission of Authoritative Parenting Style: Evidence from Japan
}

\author{
Lin Zhang $^{1} \&$ Shinsuke Ikeda ${ }^{2}$ \\ ${ }^{1}$ Faculty of Economics, Kindai University, Higashi-Osaka, Japan \\ 2 The Institute of Social and Economic Research, Osaka University, Ibaraki, Japan \\ Correspondence: Lin Zhang, Faculty of Economics, Kindai University, 3-4-1 Kowakae, Higashi-Osaka, Osaka \\ 577-8502, Japan. Tel: 81-6-4307-3235. E-mail: zhang@eco.kindai.ac.jp
}

Received: October 29, 2017

Accepted: November 22, 2017

Online Published: December 10, 2017

doi:10.5539/ijef.v10n1p64

URL: https://doi.org/10.5539/ijef.v10n1p64

\begin{abstract}
We examine and verify our hypothesis from a theoretical model that parents are more likely to be authoritative if they are from wealthy families. Using the data from the Preference Parameters Study of Osaka University, Japan, we find that there are significantly positive associations between respondents' authoritative parenting style and their family living standards when 15 years old. This result shows how childhood family economic status influences the intergenerational transmission of parenting style.
\end{abstract}

Keywords: parenting style, authoritative parenting, intergenerational transmission

\section{Introduction}

The main purpose of this study is to investigate how the childhood family economic status of parents influences their parenting style. By assessing the relation between authoritative parenting and parents' childhood family economic status, we show that it is an important factor in the transmission of authoritative parenting from one generation to the next.

Parenting behavior has increasingly been recognized as a fundamental determinant of children's development and achievement. Many psychological studies on child development investigate the relationship between one generation's child-rearing practices and that of the next generation, and find that the character of parenting behavior could be transmitted intergenerationally (for comprehensive literature reviews, see van Ijzendoorn, 1992, Putallaz, Constanzo, Grimes, \& Sherman, 1998; Belsky \& Jaffee, 2006). In other words, parents' own experiences in their childhood would influence their child-rearing attitude and practices.

Baumrind (1967, 1971, \& 1991) classifies parenting behavior into three styles: authoritative, authoritarian, and permissive. Specifically, it is found that the authoritative parenting style leads to children's later higher levels of achievement at midlife (Dornbusch, Ritter, Leiderman, Roberts, \& Fraleigh, 1987; Baumrind, 1991). However, the mechanism behind parenting style continuity across generations is not fully understood yet. Child development psychologists attempt to explain the transmission with psychological and sociological factors as a mediating pathway, such as social participation, marital satisfaction, and family structure (Chen \& Kaplan, 2001; Chen, Liu, \& Kaplan, 2008; Chan \& Koo, 2011).

Economic studies on parenting strategies mainly concentrate on how parenting style as a mediating channel influences the transmission of human capital across generations. By modelling the association between parents' economic status and their parenting practices, Weinberg (2001) shows that parents with high income levels tend to use pecuniary incentives rather than corporal punishments to influence their children's behavior. Kubota, Kamesaka, Ogaki, and Ohtake (2013) find that people's tough attitude toward children is associated with their core worldview beliefs and preferences on intertemporal decision making, such as impatience and debt aversion. Kan and Tsai (2005) and Violato, Petrou, Gray, and Redshaw (2011) empirically show that parents' current economic status influences their parenting style. Further, via different parenting styles parents' current economic characteristics impact their children's educational and behavioral outcomes. Doepke and Zilibotti (2017) develop a parent-child interaction model to describe the different parenting styles as equilibrium outcomes. Using survey data across countries, they (Doepke \& Zilibotti, 2017) empirically show that the choice of parenting styles depends on parent's preferences and the socioeconomic environmental characteristics, such as income inequality, 
and educational outcomes. Cobb-Clark, Salamanca, and Zhu (2016) show that as an investment in human capital, parenting style is associated with parents' socioeconomic disadvantage, and it is also correlated with young adults' outcome. In general, these studies focus on the current economic characteristics of parents as the determinants of parenting practices, and through their parenting behavior parents' economic resources are transmitted intergenerationally.

However, few studies link parents' childhood family economic status to their parenting styles. As pointed out by child development psychologists, parents' attitude toward parenting styles is affected by people's childhood experiences and could be transmitted across generations (van Ijzendoorn, 1992; Belsky \& Jaffee, 2006; Putallaz et al., 1998). What is the role of childhood family economic status in the mechanism of intergenerational transmission of parenting? The theoretical prediction of Zhang and Ikeda (2016) provides an interpretation.

In their study, Zhang and Ikeda (2016) proposed a parental altruism model with regard to children's habit formation, and derive the condition under which parents' authoritative behavior by keeping income transfer low raises children's lifetime welfare: children's welfare is raised when the parent is altruistic and rich enough and, hence, the amount of income transfer is large so that the children's marginal utility thereof is sufficiently small. With an underlying notion that a grown-up child, whose welfare is raised by his parent's authoritative parenting, will tend to appreciate and adopt this parenting style, it links a person's parenting style to his/her family's economic status in their childhood.

By testing the validity of this theoretical prediction with microdata, this paper aims to show that in the process of transmitting parenting style across generations, the earlier economic status of a person's family plays an important role in that parents who come from rich families are more likely to be authoritative. The results of this study support our theoretical prediction: authoritative parenting-both the demanding and responsive aspects - have a significantly positive association with parents' childhood family living standards.

The novelty of this research is that we focus on the association between generations. Unlike previous studies, which discuss the parenting strategy under parents' current economic condition, this research sheds light on the effect of parents' childhood family economic status on the transmission of authoritative parenting between generations. As the results show, one generation's economic status has an impact on the next generation's parenting style. Since authoritative parenting is an important determinant of children's future achievement (Dornbusch et al., 1987; Baumrind, 1991; Kan \& Tsai, 2005; Violato et al., 2011), in this context, this study extends the existing literature on parenting strategies and intergenerational transmission of human capital.

The rest of this paper is organized as follows. Section 2 briefly introduces the model and proposes the theoretical hypothesis. Section 3 gives the data and methodology. Section 4 shows the empirical results. Section 5 concludes.

\section{Theoretical Prediction and Hypothesis}

The hypothesis of this research is based on the theoretical result obtained by Zhang and Ikeda (2016). In their model, a child's consumption is habit forming, as it can cause overconsumption. A parent, who is aware of her child's consumption habit, restricts the child's consumption level by keeping the amount of income transfer lower than what the child desires. In this context, restricting the level of income transfer to the child corresponds to the authoritative parenting style, which is characterized by a high level of control and maturity demands in the form of active communication and induction (Baumrind, 1978).

Zhang and Ikeda (2016) show that the parent's authoritative parenting behavior enhances a child's lifetime welfare if and only if the parent is sufficiently altruistic and wealthy. Note that although it is optimal for parents, either rich or poor, to adopt authoritative parenting in this model, this parenting style is welfare-enhancing only when the parent is sufficiently wealthy. Therefore, parents from rich families, that is, parents who once experienced that authoritative parenting in their childhood enhanced their welfare, would more likely adopt the authoritative parenting style based on their experience as a child. In such families, this would contribute to the transmission of the authoritative parenting style across generations. In other words, a family's economic status plays an important role in the process of intergenerational transmission of parenting style.

Therefore, based on the prediction of the theoretical model (Zhang \& Ikeda, 2016), our hypothesis here is that authoritative parenting behavior is positively associated with the parents' past economic status in their childhood.

\section{Data and Methodology}

This research uses data from the Preference Parameters Study of Osaka University's 21st Century COE Program "Behavioral Macrodynamics Based on Surveys and Experiments" and its Global COE project "Human Behavior and Socioeconomic Dynamics". Results of the 2008 questionnaire are employed. In this survey, a random 
sample is drawn from men and women aged 20-69 years old by a self-administered placement method. The total number of respondents is 2731 , and among them the number of respondents with children is 2259 .

In order to test the hypothesis, we construct the following variables.

\subsection{Authoritative Parenting}

According to the typologies (Baumrind, 1978) of parenting styles adopted by child development psychologists, the authoritative parenting is characterized by the attempt to direct a child's activities in a rational issue-oriented manner with affection and warmth. Authoritative parents exhibit high levels of both demandingness and responsiveness. Based on these two dimensions, and following Baumrind (1978) and Doepke and Zilibotti (2017), we employ two questions (Q39 and Q40) in the survey as a measurement of authoritative parenting.

Question Q39 asks respondents about their attitude when their 5-year old children are sick:

Q39. Imagine that you have a 5-year old child that has a high fever and is in pain. The child's doctor tells you that both the fever and pain are harmless. He can give you a medicine that cures the sickness but slightly weakens the child's immune system when the child becomes 50 years old. What would you do? (Check ONE Box).

1) I would give the medicine to the child if the sickness is known to last for one day.

2) I would give the medicine to the child if the sickness is known to last for two days.

3) I would give the medicine to the child if the sickness is known to last for one week.

4) I would give the medicine to the child if the sickness is known to last for one month.

5) I would not give the medicine to the child.

As fever and pain are assumed to be harmless to the child in Q39, authoritative parenting here is to put off giving the medicine and let the child bear with the fever and pain for a while, rather than to giving a medicine that weakens the child's immune system. This question about a child's fever is close to the demanding and strict aspect of authoritative parenting. From options 1 to 5, a large number of the options indicate a high level of demandingness and strictness. We construct an ordinal variable Authoritative_Fever from Q39.

Question Q40 is about parental attitudes toward their 19-year old children who need money to buy a concert ticket:

Q40. Imagine that you have a 19-year old child that has been working at a restaurant for the last month. The child has been doing so to earn money to buy a concert ticket. You agreed that it would be all right for the child to buy the ticket as long as the child earns the necessary money. The child just got fired, and asked you to help by providing one tenth of the necessary money. The tickets will be sold out if you do not provide the money. What would you do in this situation? (Check ONE Box).

1) I would provide the money regardless of the reason why the child got fired.

2) I would provide the money if the child is not at fault for being fired.

3) I would not provide the money because it is not good for my child.

4) I would not provide the money because it will be a waste of money.

Respondents in Q40 are asked to decide whether they should give one tenth of the necessary money for a concert ticket to their children who gets fired from a part-time job. Here it is assumed that the parent has already allowed the child to buy a concert ticket with money earned from the part-time job. This question is assessing the responsiveness and supportiveness aspect of authoritative parenting. Options from 1 to 4 show different reactions of parents. Thus, we first construct a multinomial variable Authoritative_Ticket from Q40. Despite different reactions, options 1 to 3 are commonly captured by a parent's responsiveness and consideration for his/her child, while option 4 is not. The respondent who chooses the either one of the options from 1 to 3 is labeled as responsive and supportive, and a binary variable Authoritative_Responsiveness is also constructed from Q40.

\subsection{Habit Awareness}

According to the typologies on parenting styles (Baumrind, 1978), both authoritative and authoritarian parents exhibit a high level of demandingness. However, authoritarian parenting shows little responsiveness or supportiveness. This feature distinguishes authoritative parents from the authoritarian ones. Authoritarian parents exert strict control just because they want obedience, and not for the sake of improving the child's future outcome. 
In the theoretical model (Zhang \& Ikeda, 2016), the authoritative parent is aware that consumption is habit-forming, while the child is not. Being unaware of the habit-forming nature of consumption, the child tends to overconsume, which will worsen his lifetime welfare. Hence, the authoritative parent tends to keep the income transfer to the child low in order to raise his lifetime welfare.

Therefore, in this context, indicating that whether the respondents are aware of habit formation helps distinguish authoritative parenting from the authoritarian style. To identify whether our respondents are actually aware of it, we check their responses to the following two questions about living standards (Q3-03 and Q15):

Q3-03. How true for you are each of the following statements? Answer for each on a scale from 1 to 5, where "1" means it is particularly true for you and " 5 " means "it doesn't hold true at all for you. (Check ONE Box for EACH).

Once I enjoy a high standard of living, it is painful to lower it.

Q15. Suppose that your housing and the necessities of life will be provided by the government for the next ten years. If there is a limit on the overall provision, which pattern would you choose? (Check ONE Box).

1) Start from higher living standard, then lower it gradually.

2) Same living standard every year.

3) Start from lower living standard, then raise it gradually.

Theoretically, habit formation of consumption implies that a consumer's marginal utility is increased by past consumption, and a child who does not realize it tends to overconsume. Our habit awareness indicator, Habit_Aware, is jointly constructed from Q3-03 and Q15.

Question Q3-03 concerns the ratchet effect of standard of living, which implies that people's consumption level is irreversible (Note 1). Habit formation weakens a consumer's tolerance of declining living standards and makes $\mathrm{him} / \mathrm{her}$ exhibit the ratchet effect. Hence, a consumer who is aware of habit formation would report that he/she feels pained to lower the standard of living after experiencing high living standard.

Question Q15 asks whether the respondent has any preference for improvement in his/her higher standard of living. Habit formation is an important factor that causes a consumer to seek an increasing living standard (see Easterlin, 1974; Easterlin, 1995; Loewenstein \& Prelec, 1991). Consumers who are aware of the habit-forming nature of consumption would prefer the upward time profile of the living standard.

We label those respondents who report "1" or "2" in Q3-03 and at the same time "3" in Q15 as being aware of habit formation.

\subsection{Family Living Standard}

According to the result of the model proposed by Zhang and Ikeda (2016), authoritative parenting style of keeping income transfer to children low is in fact welfare-enhancing to the children only if the parents are rich enough. This implies that the family economic status during childhood years is a critical factor for parents to adopt authoritative parenting. To measure the childhood family economic status, we construct an 11 -scale variable Family_Living_Standard from the question FQ44 about the family's standard of living when the respondent was 15 years old:

FQ44. On a scale of $0-10$ with "10" being "Highest" and " 0 " being "Lowest", please indicate what you think was the standard of living for your family when you were 15 years old. (Check ONE Box)

Highest

Lowest

$\begin{array}{lllllllllll}10 & 9 & 8 & 7 & 6 & 5 & 4 & 3 & 2 & 1 & 0\end{array}$

Table 1 reports the descriptive statistics of the variables.

Table 1. Descriptive statistics

\begin{tabular}{lcccccc}
\hline & \multicolumn{3}{c}{ Parent sample } & \multicolumn{3}{c}{ Whole sample } \\
\cline { 2 - 7 } & \#obs. & Mean & S.D. & \#obs. & Mean & S.D. \\
\hline Authoritative_Fever & 2,229 & 3.450 & 1.236 & 2,681 & 3.473 & 1.238 \\
Authoritative_Ticket & 2,234 & 1.994 & 0.575 & 2,689 & 1.997 & 0.581 \\
Habit_Aware & 2,212 & 0.170 & 0.375 & 2,670 & 0.177 & 0.382 \\
Family_Living_Standard & 2,240 & 4.568 & 1.831 & 2,703 & 4.623 & 1.818 \\
\hline
\end{tabular}




\section{Results}

First, we test our theoretical hypothesis by investigating how childhood family economic status influences authoritative parenting from the aspect of demandingness with ordered logit models. The dependent variable (Authoritative_Fever) is from the fever question Q39. The independent variable is the family's living standard when the respondent was 15 years old (Family_Living_Standard), which is a proxy variable for the respondent's childhood family economic status. Control variables age, age squared, female indicator, and bachelor's degree (or higher) indicator are included (Note 2).

Table 2 summarizes the regression results. Recall that a high level of demandingness appears in both authoritative and authoritarian parenting (Baumrind, 1978), and the indicator Habit_Aware enables us to separate them from each other. In other words, habit awareness is critical when examining how family's childhood economic status is associated with the demanding aspect of authoritative parenting.

Table 2. Authoritative parenting demandingness and childhood family economic status

\begin{tabular}{lcccccc}
\hline & $(1)$ & $(2)$ & $(3)$ & $(4)$ & $(5)$ & $(6)$ \\
\cline { 2 - 7 } & \multicolumn{2}{c}{ Habit_Aware= 1} & \multicolumn{2}{c}{ Habit_Aware=0 } & \multicolumn{2}{c}{ Habit_Aware Removed } \\
\hline Family_Living_Standard & $0.108^{* *}$ & $0.101^{* *}$ & 0.002 & -0.009 & 0.027 & 0.018 \\
& $(0.054)$ & $(0.048)$ & $(0.025)$ & $(0.023)$ & $(0.022)$ & $(0.021)$ \\
Age & 0.055 & 0.039 & -0.017 & 0.015 & -0.010 & 0.016 \\
& $(0.075)$ & $(0.050)$ & $(0.036)$ & $(0.025)$ & $(0.032)$ & $(0.022)$ \\
Age sq. & -0.001 & 0.000 & 0.000 & 0.000 & 0.000 & 0.000 \\
Female & $(0.001)$ & $(0.001)$ & $(0.000)$ & $(0.000)$ & $(0.000)$ & $(0.000)$ \\
& -0.188 & -0.142 & 0.000 & 0.039 & -0.047 & -0.006 \\
Bacheloryyyyyyyy & $(0.208)$ & $(0.183)$ & $(0.092)$ & $(0.083)$ & $(0.083)$ & $(0.075)$ \\
& 0.095 & 0.167 & 0.149 & 0.246 & 0.109 & $0.204 * *$ \\
\#obs. & $(0.217)$ & $(0.190)$ & $(0.118)$ & $(0.105)$ & $(0.102)$ & $(0.090)$ \\
\hline
\end{tabular}

Note. Standard errors in parentheses. ${ }^{* * *} \mathrm{p}<0.01,{ }^{*} \mathrm{p}<0.05,{ }^{*} \mathrm{p}<0.1$. Dependent variable: Authoritative_Fever. Columns (1), (3) and (5) include the respondents with children, while columns (2), (4) and (6) include all. All the models are ordered logistic regressions.

As shown in Table 2, authoritative parenting has significantly positive associations with Family_Living_Standard when the respondents are aware of the effect of habit $($ Habit_Aware=1). In contrast, for the sample in which the respondents are unaware of habit (Habit_Aware=0), the coefficients of Family_Living_Standard are not significant. In the case where habit awareness is not considered (column (5) and (6)), the coefficients are not significant either. These results commonly support out hypothesis.

Next, we examine the theoretical hypothesis from the aspect of responsiveness. Following Doepke and Zilibotti (2017), we regress parenting style in multinomial models. Multinomial variable Authoritative_Ticket from Q40 is employed as the dependent variable. Table 3 shows the results of multinomial regressions, where option 4 of Q40 is the reference category in all the models.

In Table 3, the coefficients of Family_Living_Standard are the relative risk ratios for options 1 to 3 versus option 4. Each one of the options from 1 to 3 exhibits responsiveness and supportiveness, while option 4 does not. Hence, these coefficients show the relative risk ratios associated with respondents' family economic status for responsiveness versus non-responsiveness. Note that habit awareness is not a critical factor for responsiveness or supportiveness. Therefore, when the Habit_Aware indicator is not considered, options 1, 2, and 3 all have a significantly positive association with Family_Living_Standard. Even in the case that Habit_Aware indicator is considered (Habit_Aware=1 or Habit_Aware=0), significantly positive coefficients of Family_Living_Standard still exist. Therefore, we conclude that the responsive aspect of authoritative parenting is positively associated with family economic status, which is consistent with the theoretical hypothesis.

Furthermore, we process principal component analysis to investigate the common tendency of authoritative parenting's two aspects and its relation with childhood family economic status. Note that although questions Q39 and Q40 focus on different aspects of authoritative parenting, they both contain a common feature that defines authoritative parenting: parents' supervision of their children's behavior with consideration and involvement. The demanding aspect and responsive aspect are not opposite or exclusive of each other, but jointly formalize the authoritative parenting (Maccoby \& Martin, 1983). 
Table 3. Authoritative parenting responsiveness and childhood family economic status

\begin{tabular}{|c|c|c|c|c|c|c|}
\hline & \multicolumn{6}{|c|}{ Reference Category: Option 4} \\
\hline & $(1)$ & $(2)$ & (3) & (4) & $(5)$ & $(6)$ \\
\hline & \multicolumn{6}{|c|}{ Habit_Aware Removed } \\
\hline & \multicolumn{2}{|c|}{ Option 1} & \multicolumn{2}{|c|}{ Option 2} & \multicolumn{2}{|c|}{ Option 3} \\
\hline \multirow[t]{2}{*}{ Family_Living_Standard } & $0.308^{* * *}$ & $0.286^{* * *}$ & $0.291 * * *$ & $0.274 * * *$ & $0.274 * *$ & $0.259 * *$ \\
\hline & $(0.113)$ & $(0.099)$ & $(0.110)$ & $(0.096)$ & $(0.114)$ & $(0.100)$ \\
\hline \multirow[t]{2}{*}{ Age } & 0.130 & 0.114 & -0.107 & 0.014 & -0.077 & 0.014 \\
\hline & $(0.196)$ & $(0.117)$ & $(0.189)$ & $(0.112)$ & $(0.195)$ & $(0.117)$ \\
\hline \multirow[t]{2}{*}{ Age sq. } & -0.001 & -0.001 & 0.001 & 0.000 & 0.001 & 0.000 \\
\hline & $(0.002)$ & $(0.001)$ & $(0.002)$ & $(0.001)$ & $(0.002)$ & $(0.001)$ \\
\hline \multirow[t]{2}{*}{ Female } & 0.114 & -0.130 & 0.578 & 0.476 & $0.838^{* *}$ & $0.691 * *$ \\
\hline & $(0.418)$ & $(0.357)$ & $(0.405)$ & $(0.344)$ & $(0.424)$ & $(0.362)$ \\
\hline \multirow[t]{2}{*}{ Bachelor's Degree } & 0.346 & 0.615 & 0.330 & 0.744 & 0.422 & 0.733 \\
\hline & $(0.578)$ & $(0.560)$ & $(0.566)$ & $(0.549)$ & $(0.587)$ & $(0.566)$ \\
\hline \multirow[t]{5}{*}{ \#obs. } & 2155 & 2568 & 2155 & 2568 & 2155 & 2568 \\
\hline & \multicolumn{6}{|c|}{ Reference Category: Option 4} \\
\hline & $(1)$ & $(2)$ & (3) & (4) & $(5)$ & $(6)$ \\
\hline & \multicolumn{6}{|c|}{ Habit_Aware=1 } \\
\hline & \multicolumn{2}{|c|}{ Option 1} & \multicolumn{2}{|c|}{ Option 2} & \multicolumn{2}{|c|}{ Option 3} \\
\hline \multirow[t]{2}{*}{ Family_Living_Standard } & $0.600 * *$ & $0.685^{* *}$ & $0.671 * *$ & $0.754 * * *$ & $0.684 * *$ & $0.752 * * *$ \\
\hline & $(0.288)$ & $(0.280)$ & $(0.281)$ & $(0.275)$ & $(0.295)$ & $(0.287)$ \\
\hline \multirow[t]{2}{*}{ Age } & -1.001 & $0.522 * *$ & -1.197 & $0.440 * *$ & -1.087 & $0.587 * *$ \\
\hline & $(1.770)$ & $(0.239)$ & $(1.766)$ & $(0.227)$ & $(1.771)$ & $(0.249)$ \\
\hline \multirow[t]{2}{*}{ Age sq. } & 0.006 & $-0.005 * *$ & 0.008 & $-0.005 * *$ & 0.007 & $-0.006^{* *}$ \\
\hline & $(0.014)$ & $(0.002)$ & $(0.014)$ & $(0.002)$ & $(0.014)$ & $(0.002)$ \\
\hline \multirow[t]{2}{*}{ Female } & 0.516 & 0.897 & 0.967 & 1.400 & 1.837 & $2.127 * *$ \\
\hline & $(1.220)$ & (1.178) & $(1.192)$ & $(1.156)$ & $(1.245)$ & $(1.201)$ \\
\hline \multirow[t]{2}{*}{ Bachelor's Degree } & -0.711 & 0.199 & 0.049 & 0.730 & 0.882 & 1.412 \\
\hline & 1.273 & $(1.195)$ & $(1.228)$ & $(1.165)$ & $(1.276)$ & $(1.209)$ \\
\hline \multirow[t]{5}{*}{ \#obs. } & 364 & 454 & 364 & 454 & 364 & 454 \\
\hline & \multicolumn{6}{|c|}{ Reference Category: Option 4} \\
\hline & $(1)$ & $(2)$ & (3) & (4) & $(5)$ & $(6)$ \\
\hline & & & Habi & vare $=0$ & & \\
\hline & & on 1 & & on 2 & & \\
\hline Family_Living_Standard & $0.265^{* *}$ & $0.258 * *$ & $0.228^{* *}$ & $0.223 * *$ & 0.200 & $0.205^{* *}$ \\
\hline & $(0.131)$ & $(0.114)$ & $(0.127)$ & $(0.111)$ & $(0.132)$ & $(0.115)$ \\
\hline Age & -0.021 & -0.004 & -0.271 & -0.105 & -0.261 & -0.130 \\
\hline & $(0.233)$ & $(0.145)$ & $(0.226)$ & $(0.140)$ & $(0.232)$ & $(0.145)$ \\
\hline Age sq. & 0.000 & 0.000 & 0.002 & 0.001 & 0.003 & 0.001 \\
\hline & $(0.002)$ & $(0.001)$ & $(0.002)$ & $(0.001)$ & $(0.002)$ & $(0.001)$ \\
\hline Female & 0.208 & -0.258 & 0.668 & 0.362 & $0.829 * *$ & 0.496 \\
\hline & $(0.470)$ & $(0.401)$ & $(0.456)$ & $(0.387)$ & $(0.476)$ & $(0.406)$ \\
\hline Bachelor's Degree & 1.007 & 1.095 & 0.835 & 1.132 & 0.682 & 0.942 \\
\hline & $(0.778)$ & $(0.761)$ & $(0.767)$ & $(0.751)$ & $(0.791)$ & $(0.770)$ \\
\hline \#obs. & 1759 & 2073 & 1759 & 2073 & 1759 & 2073 \\
\hline
\end{tabular}

Note. Standard errors in parentheses. $* * * \mathrm{p}<0.01,{ }^{*} \mathrm{p}<0.05,{ }^{*} \mathrm{p}<0.1$. Dependent variable: Authoritative_Ticket. Columns (1), (3) and (5) include the respondents with children, while columns (2), (4) and (6) include all. All the models are multinomial logistic regressions.

Due to its nature, the multinomial variable Authoritative_Ticket cannot be used in the principal component analysis. Instead, a binary indicator from Q40 (Authoritative_Responsiveness) is constructed. In order to extract common information, respondents' inclination toward authoritative parenting, a principal component analysis of these two original variables is carried. The results are shown in Table 4. We construct a new variable, Authoritative_PC, which is the first principal component of Authoritative_Fever and Authoritative_Responsiveness. As shown in Table 4, Authoritative_PC, consisting of both demandingness and 
responsiveness, is an integrated and comprehensive measure of authoritative parenting. The value of the first principal component, i.e., the factor score, is also calculated for each respondent.

Table 4. Principal component analysis of demandingness and responsiveness

\begin{tabular}{lcc}
\hline \multicolumn{1}{c}{ Principal Component } & Component 1 & Component 2 \\
\hline Factor Loading on Authoritative_Fever & 0.707 & 0.707 \\
Factor Loading on Authoritative_Responsiveness & 0.707 & -0.707 \\
\hline Variation Explained (\%) & 52.2 & 47.8 \\
\hline
\end{tabular}

In Figure 1 and Figure 2, we graphically examine how the value of the first principal component of the two original variables (Authoritative_PC) relates with the level of family living standards at the age of 15 years (Family_Living_Standard) in the groups of Habit_Aware $=1$ and Habit_Aware $=0$. The respondents are categorized by their family living standards during childhood, which is shown as the horizontal axis. The mean values of respondents' factor score at different levels of family living standards are plotted, with $95 \%$ confidence intervals. Note that a larger value on the vertical axis represents a stronger inclination for authoritative parenting.

Consistent with our hypothesis, Figure 1 shows that the mean value of Authoritative_PC increases with the respondents' family living standard when they are aware of the effect of habit formation. In contrast, Figure 2 shows that such a correlation cannot be observed for respondents who are unaware of habit formation.

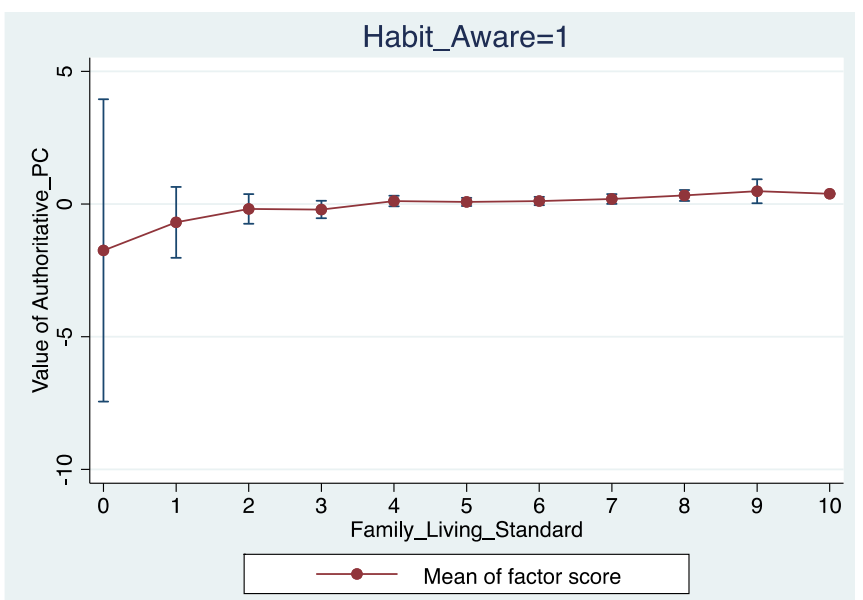

Figure 1. Principal component and family living standard under habit awareness

Note. $95 \%$ confidence intervals shown.

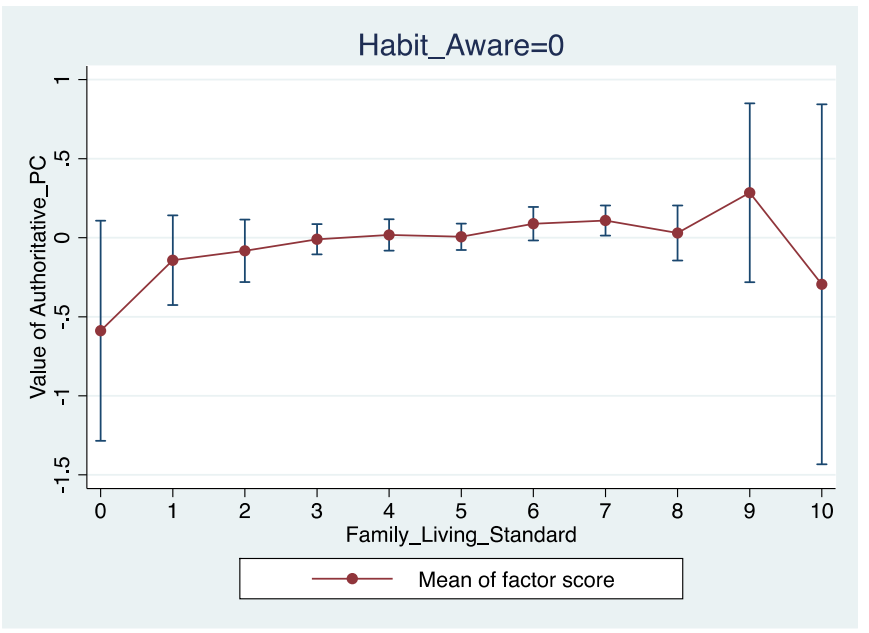

Figure 2. Principal component and family living standard under habit unawareness 
To examine the association between authoritative parenting and childhood family living standards more clearly, we regress Authoritative_PC on Family_Living_Standard. As shown in Table 5, the results still support our hypothesis. Authoritative_PC is positively associated with respondents' family economic status (Family_Living_Standard) in the group of habit awareness (Habit_Aware=1). Even when habit awareness is not considered, this significantly positive association still exists. This is because responsiveness and consideration are integrated, which distinguish authoritative from authoritarian. However, in the group of habit unawareness, this significant association is hardly observed.

Table 5. Authoritative_PC and childhood family economic status

\begin{tabular}{|c|c|c|c|c|c|c|}
\hline & (1) & (2) & (3) & (4) & (5) & (6) \\
\hline & \multicolumn{2}{|c|}{ Habit_Aware=1 } & \multicolumn{2}{|c|}{ Habit_Aware $=0$} & \multicolumn{2}{|c|}{ Habit_Aware Removed } \\
\hline \multirow[t]{2}{*}{ Family_Living_Standard } & $0.091 * * *$ & $0.084 * * *$ & 0.018 & 0.016 & $0.033^{* * *} *$ & $0.031 * * *$ \\
\hline & $(0.029)$ & $(0.025)$ & $(0.013)$ & $(0.013)$ & $(0.012)$ & $(0.011)$ \\
\hline \multirow[t]{2}{*}{ Age } & $0.077^{* *}$ & $0.065^{* *}$ & -0.020 & 0.003 & -0.003 & 0.012 \\
\hline & $(0.040)$ & $(0.027)$ & $(0.019)$ & $(0.014)$ & $(0.017)$ & $(0.012)$ \\
\hline \multirow[t]{2}{*}{ Age sq. } & $-0.001 * *$ & $-0.001 * * *$ & 0.000 & 0.000 & 0.000 & 0.000 \\
\hline & $(0.000)$ & $(0.000)$ & $(0.000)$ & $(0.000)$ & $(0.000)$ & $(0.000)$ \\
\hline \multirow[t]{2}{*}{ Female } & -0.004 & 0.044 & 0.059 & 0.055 & 0.038 & 0.049 \\
\hline & $(0.114)$ & $(0.097)$ & $(0.050)$ & $(0.046)$ & $(0.045)$ & $(0.042)$ \\
\hline \multirow[t]{2}{*}{ Bachelor's Degree } & 0.043 & 0.108 & $0.120^{* *}$ & $0.165 * * *$ & 0.076 & $0.134 * * *$ \\
\hline & $(0.121)$ & $(0.102)$ & $(0.064)$ & $(0.058)$ & $(0.056)$ & $(0.051)$ \\
\hline \#obs. & 362 & 452 & 1749 & 2058 & 2143 & 2551 \\
\hline
\end{tabular}

Note. Standard errors in parentheses. ${ }^{* *} * \mathrm{p}<0.01, * * \mathrm{p}<0.05,{ }^{*} \mathrm{p}<0.1$. Dependent variable: Authoritative_PC (the first principal component of Authoritative_Fever and Authoritative_Responsiveness). Columns (1), (3) and (5) include the respondents with children, while columns (2), (4) and (6) include all. All the models are OLS regressions.

\section{Concluding Remarks}

We investigate the theoretical prediction (Zhang \& Ikeda, 2016) that people from wealthy families are more likely to be authoritative parents. We examine the hypothesis from the two underlying dimensions of parenting style, demandingness and responsiveness. Consistent with the theoretical result, we find that the demanding aspect and the responsive aspect are both positively associated with the family's living standard when the respondent was 15 years old. Additionally, authoritative parenting, which is jointly formalized from these two aspects, is also positively associated with respondents' childhood family economic status. The empirical results of this study validate the theoretical model proposed by Zhang and Ikeda (2016) and expand childhood family economic status to the mechanism of intergenerational parenting style transmission. Therefore, parents' childhood experiences, i.e., their childhood family economic status, play an essential role in the transmission of authoritative parenting from one generation to the next. Our research results are related with intergenerational transmission of human capital and intergenerational mobility. The results provide explanation and evidence for studies on intergenerational persistence in income and social class from the aspect of parenting style by showing the important effect of one's childhood family economic status.

\section{Acknowledgments}

Ikeda has received financial support of: Grants-in-Aid for Scientific Research (C No. 26380239; B No. 17H02499) from the Japan Society for the Promotion of Science; and the Joint Usage/ Research Center Project of ISER from the Ministry of Education, Culture, Sports, Science and Technology. Zhang has received Grant-in-Aid for Young Scientists (B No. 16K17140) from the Japan Society for the Promotion of Science. This research uses microdata from the Preference Parameters Study of Osaka University's 21st Century COE Program "Behavioral Macrodynamics Based on Surveys and Experiments" and its Global COE project "Human Behavior and Socioeconomic Dynamics". We acknowledge the program/project's contributors: Yoshiro Tsutsui, Fumio Ohtake, and Shinsuke Ikeda.

\section{References}

Baumrind, D. (1967). Child care practices anteceding three patterns of preschool behavior. Genetic Psychology Monographs, 75(1), 43-88. http://dx.doi.org/10.4135/9781473915435

Baumrind, D. (1971). Current patterns of parental authority. Developmental Psychology, 4, 1-103. http://dx.doi.org/10.1037/h0030372 
Baumrind, D. (1978). Parental disciplinary patterns and social competence in children. Youth \& Society, 9(3), 239-267. https://doi.org/10.1177/0044118X7800900302

Baumrind, D. (1991). Parenting styles and adolescent development. The Encyclopedia of Adolescence (pp. 746-758). Garland, New York.

Belsky, J., \& Jaffee, S. (2006). The multiple determinants of parenting. Developmental psychopathology: 3. Risk, disorder and adaptation (2nd ed., pp. 38-85). New York: Wiley. https://doi.org/10.1002/9780470939406.ch2

Chan, T. W., \& Koo, A. (2011). Parenting style and youth outcomes in the UK. European Sociological Review, 27(3), 385-399. https://doi.org/10.1093/esr/jcq013

Chen, Z., \& Kaplan, H. B. (2001). Intergenerational transmission of constructive parenting. Journal of Marriage and Family, 63, 17-31. https://doi.org/10.1111/j.1741-3737.2001.00017.x

Chen, Z. Y., Liu, R. X., \& Kaplan, H. B. (2008). Mediating mechanisms for the intergenerational transmission of constructive parenting: A prospective longitudinal study. Journal of Family Issues, 29(12), 1574-1599. https://doi.org/10.1177/0192513X08318968

Cobb-Clark, D. A., Salamanca, N., \& Zhu, A. (2016). Parenting style as an investment in human development. IZA Discussion Paper, No. 9686.

Doepke, M., \& Zilibotti, F. (2017). Parenting with style: Altruism and paternalism in intergenerational preference transmission. Econometrica, 85(5), 1331-1371. https://doi.org/10.3982/ECTA14634

Dornbusch, S. M., Ritter, P. L., Leiderman, P. H., Roberts, D. F., \& Fraleigh, M. J. (1987). The relation of parenting style to adolescent school performance. Child Development, 58(5), 1244-1257. http://dx.doi.org/10.2307/1130618

Duesenberry, J. S. (1949). Income, saving, and the theory of consumer behavior. Cambridge, Mass.: Harvard University Press. http://dx.doi.org/10.2307/1926590

Easterlin, R. A. (1974). Does economic growth improve the human lot? Some empirical evidence. In Nations and Households in Economic Growth: Essays in Honor of Moses Abramovitz. New York: Academic Press, Inc. http://dx.doi.org/10.1016/b978-0-12-205050-3.50008-7

Easterlin, R. A. (1995). Will raising the incomes of all increase the happiness of all? Journal of Economic Behavior \& Organization, 27(1), 35-47. https://doi.org/10.1016/0167-2681(95)00003-B

van Ijzendoorn, M. H. (1992). Intergenerational transmission of parenting: A review of studies in nonclinical populations. Developmental Review, 12, 76-99. https://doi.org/10.1016/0273-2297(92)90004-L

Kan, D., \& Tsai, W. D. (2005). Parenting practices and children's education outcomes. Economics of Education Review, 24, 29-43. https://doi.org/10.1016/j.econedurev.2004.04.006

Kubota, K., Kamesaka, A., Ogaki, M. \& Ohtake, F. (2013). Cultures, worldviews, and intergenerational altruism. European Regional Science Association conference paper.

Loewenstein, G., \& Prelec, D. (1991). Negative time preference. The American Economic Review, 81(2), 347-352. Papers and Proceedings of the Hundred and Third Annual Meeting of the American Economic Association.

Maccoby, E. E., \& Martin, J. M. (1983). Socialization in the context of the family: Parent-child interaction. Handbook of child psychology: Socialization, personality, and social development. New York: Wiley.

Putallaz, M., Constanzo, P. R., Grimes, C. L., \& Sherman, D. M. (1998). Intergenerational continuities and their influences on children's social development. Social Development, 7 , 389-427. http://dx.doi.org/10.1111/1467-9507.00074

Violato, M., Petrou, S., Gray, R., \& Redshaw, M. (2011). Family income and child cognitive and behavioural development in the United Kingdom: Does money matter? Health Economics, 20, 1201-1225. http://dx.doi.org/10.1002/hec.1665

Weinberg, A. B. (2001). An incentive model of the effect of parental income on children. Journal of Political Economy, 109(2), 266-280. http://dx.doi.org/10.1086/319556

Zhang, L., \& Ikeda, S. (2016). Welfare-enhancing parental altruism and children's habit formation. International Review of Economics, 63(3), 281-303. https://doi.org/10.1007/s12232-016-0255-2 


\section{Notes}

Note 1. Duesenberry (1949) argues that consumption as a proportion of income rises as income increases and does not fall in the same proportion when the income declines. This is called the "ratchet effect".

Note 2. There is multicollinearity between the annual income of the entire household and other independent variables. Further, if it is included as a control variable, the coefficient of annual income of the entire household is not significant.

\section{Copyrights}

Copyright for this article is retained by the author(s), with first publication rights granted to the journal.

This is an open-access article distributed under the terms and conditions of the Creative Commons Attribution license (http://creativecommons.org/licenses/by/4.0/). 